\title{
Prediction of in-hospital death from community-acquired pneumonia by varying CRB-age groups
}

\author{
Santiago Ewig*, Torsten Bauer*, Klaus Richter", Joachim Szenscenyi", \\ Günther Heller", Richard Strauss ${ }^{+}$and Tobias Welte ${ }^{\S}$
}

ABSTRACT: $\mathrm{C}(\mathrm{U}) \mathrm{RB}-65$ (confusion, (urea $>7 \mathrm{~mol} \cdot \mathrm{L}^{-1}$,) respiratory frequency $\geqslant 30$ breaths $\cdot \mathrm{min}^{-1}$, systolic blood pressure $<90 \mathrm{mmHg}$ or diastolic blood pressure $\leqslant 60 \mathrm{mmHg}$ and age $\geqslant 65$ years) is now the generally accepted severity score for patients with community-acquired pneumonia (CAP) in Europe.

In an observational study based on the large database from the German nationwide performance measurement programme in healthcare quality, including data from all hospitalised patients with CAP during 2008-2010, different CRB-age groups ( $\geqslant 50$ and $\geqslant 60$ years) across the total CAP population and three entities of CAP (younger population aged $<65$ years, patients aged $\geqslant 65$ years not residing in nursing homes and those with nursing home-acquired pneumonia (NHAP)) were validated for their potential to predict in-hospital death.

660594 patients were investigated. Mortality was $n=93958$ (14.0\%). In the total population, CRB-80 had the optimal area under the curve $(0.690,95 \% \mathrm{Cl} 0.688-0.691)$. However, in the younger cohort, CRB-50 performed best $(0.730,95 \% \mathrm{Cl} 0.724-0.736)$, with good identification of low-risk patients (CRB-50 risk class 1: 1.28\% deaths, negative predictive value 98.7\%). In the elderly, CRB-80 as the optimal age group performed worse $(0.663,95 \% \mathrm{Cl} 0.660-0.655$ in patients not residing in nursing homes; $0.608,95 \% \mathrm{CI} 0.605-0.611$ in those with NHAP). In the latter group, all CRB-age groups failed to identify low-risk patients (CRB-80 risk class 1: $22.75 \%$ deaths,

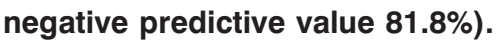

Patients with hospitalised CAP aged $<65$ years may be assessed by the CRB-50 score. In those aged $\geqslant 65$ years (not NHAP) assessed by the CRB-65 score, low-risk patients are already are at an increased risk of death. In NHAP patients, even the use of CRB-80 does not identify low-risk patients and should be accompanied by the evaluation of functional status and comorbidity.

KEYWORDS: Infectious diseases epidemiology, respiratory infection

$\mathbf{T}$ he assessment of pneumonia severity is now recognised as one of the most important steps in the management of patients with community-acquired pneumonia (CAP). In Europe, CURB-65 (confusion, urea $>7 \mathrm{~mol} \cdot \mathrm{L}^{-1}$, respiratory frequency $\geqslant 30$ breaths $\cdot \mathrm{min}^{-1}$, systolic blood pressure $<90 \mathrm{mmHg}$ or diastolic blood pressure $\leqslant 60 \mathrm{mmHg}$ and age $\geqslant 65$ years) and its variation (CRB-65) have gained general acceptance as a tool for severity assessment because of its favourable predictions comparable to the more complex pneumonia severity index (PSI) and its fabulous simplicity $[1,2]$.
The simplicity of this tool is a major advantage that cannot be outweighed by the potential small improvements of predictive power gained by introducing additional variables. However, the optimal cut-off of the variable "age" has not been determined, and concerns have been raised about the appropriate age cut-off in the elderly population [3, 4]. As it stands, the cut-off of 65 years appears arbitrary. Conversely, whereas crude age has a major impact on mortality and different cut-offs of age may considerably impact the predictive power of the tool, it has not been settled whether age is an independent risk factor

\section{AFFILIATIONS}

*Thoraxzentrum Ruhrgebiet, Dept of Respiratory and Infectious Diseases, EVK Herne and Augusta-KrankenAnstalt Bochum, Bochum,

\#Helios Klinikum Emil von Behring, Lungenklinik Heckeshorn, Berlin,

•Aqua-Institut Göttingen, Göttingen, +Medical Dept, Universitätsklinikum Erlangen, Erlangen, and ${ }^{\S}$ Dept of Pneumology, Hannover University, Hannover, Germany.

\section{CORRESPONDENCE}

S. Ewig

Thoraxzentrum Ruhrgebiet Kliniken für Pneumologie und Infektiologie EVK Herne und Augusta-KrankenAnstalt Bochum Bergstrasse 26 44791 Bochum Germany

E-mail: ewig@augusta-bochum.de

Received:

April 212012

Accepted after revision: July 172012

First published online: Aug 162012 
for death [4-6]. Moreover, setting the cut-off for age is particularly important in view of the fact that the high weight of advanced age may negatively impact the sensitivity for high risk of death in younger patients [2].

We showed recently $[7,8]$ that CAP should be regarded as a condition comprising three entities with highly different prognostic implications: younger patients (aged $<65$ years), elderly patients not residing in nursing homes ( $\geqslant 65$ years) and elderly patients with nursing home-acquired pneumonia (NHAP). In the present analysis, we provide a validation of different CRB-age groups across the total CAP population and the three entities of CAP, based on the large database from the German nationwide performance measurement programme in healthcare quality including data from all hospitalised patients with CAP over a 3-year period.

\section{METHODS}

\section{Database}

This observational study is based on the database from a nationwide mandatory performance measurement programme in Germany, established in 2005. All hospitals are required to provide a set of data defined by an expert group on CAP together with the Aqua Institut of Healthcare (formerly, until 2009, with the Bundesgeschäftsstelle für Qualitätssicherung).

CAP is identified by encoding pneumonia without severe immunosuppression (HIV infection, solid organ or bone marrow/stem cell transplants or severe neutropenia) as the principal diagnosis of hospital admission. The underlying International Classification of Diseases (ICD)-10 German modification (GM) is used for the inclusion and exclusion of cases. These codes clearly exclude acute bronchitis and exacerbations of chronic obstructive pulmonary disease as well as nosocomial pneumonia.

The database included all hospitalised patients with acute CAP regardless of where they presented initially. Since patients presenting with CAP in hospital in Germany are usually admitted, the group of patients safely discharged from the emergency room is considered to be minimal. The use of CRB-65 score is recommended by German CAP guidelines; however, there are no data about compliance with this recommendation.

The database comprised information on the referral mode (from home, nursing home, another hospital or rehabilitation facilities), age and sex, comorbidities according to ICD-10-GM (optional), functional condition, respiratory rate, systolic and diastolic blood pressure, presence of acute pneumonia-related mental confusion at admission, the use of ventilatory support (noninvasive or invasive), the presence of stability criteria at discharge (including respiratory rate, systolic and diastolic blood pressure, and mental state) and outcome (survival or death). These data are assessed electronically. Data on pathogen patterns and choices of antimicrobial treatment are not available. Further details have been published elsewhere [9].

For the purpose of this analysis, a dataset including three most recent years was chosen (2008-2010). The database had no missing data except comorbidity, since the entry of the variables was mandatory.

\section{CRB-age groups}

CRB was calculated, assigning one point in the presence of each of 1) pneumonia-associated mental confusion, 2) respiratory rate $\geqslant 30$ breaths $\cdot \mathrm{min}^{-1}$ and 3 ) systolic blood pressure $<90 \mathrm{mmHg}$ or diastolic blood pressure $\leqslant 60 \mathrm{mmHg}$.

The analysis of the predictive potential of CRB-age groups for in-hospital mortality was performed by assigning different cutoffs for age $(\geqslant 30, \geqslant 40, \geqslant 50, \geqslant 60, \geqslant 65, \geqslant 70, \geqslant 80, \geqslant 90$ and $\geqslant 100$ years) to the categorisation according to CRB criteria.

CRB-age group classifications resulting in groups (0-4) were recalculated into risk classes in a modified way according to LiM et al. [1]. Risk classes were calculated as follows: risk class (RC)-1 (CRB-65 0 points); RC-2 (CRB-65 1-2 points); RC-3 (CRB-65 3-4 points or mechanical ventilation at admission, since no reliable assessment of respiratory rate is realistic in these latter patients).

CRB-age groups were tested for predictions of in-hospital mortality in the general population and the three entities of CAP: younger (aged $<65$ years), the elderly not residing in nursing homes ( $\geqslant 65$ years) and the elderly with NHAP.

\section{Statistics}

Multivariable analysis for independent predictors of inhospital death of patients admitted with CAP was performed by stepwise forward logistic regression. In order to investigate the relative weight of decade of age, CRB, nursing home residence and bedridden functional status, only these four variables were included. The predictive performance for inhospital death in patients with CAP was presented, listing the predictions of $\mathrm{CRB}$-age groups according to CRB-age group risk classes, and calculating sensitivity (true positives (CRB-age group RC-2 and -3)/all deaths), specificity (true negatives (CRBage group RC-1/all alive), as well as positive (true positives/all positives) and negative (true negatives/all negatives) predictive values. In addition, these were formally assessed by building receiver operating characteristic (ROC) curves and calculating the area under the curve (AUC). The level of significance was set at $\mathrm{p}<0.05$.

\section{RESULTS \\ Patient population}

Overall, 660594 patients $(2008 n=211708 ; 2009 n=229796$ and $2010 \mathrm{n}=228$ 090) hospitalised with CAP in Germany in 20082010 were included. Mean age was 72.81 (95\% CI 71.40-74.22) and the ratio of males to females was 55.8:44.2.

The characteristics of these patients and the distribution of CRB-65 risk classes are provided in table 1 .

\section{Mortality}

Total in-hospital mortality was 93958 (14.0\%) (2008 n=30 373, 14.3\%; $2009 \mathrm{n}=32$ 414, 14.1\%; $2010 \mathrm{n}=31$ 171, 13.7\%).

Mortality increased according to increasing age, nursing-home residency and bedridden functional status. Distribution of mortality rates stratified into patients aged $<65$ years, $\geqslant 65$ years and not residing in nursing homes and $\geqslant 65$ years with NHAP is given in figure 1; distribution of mortality rates stratified according to age, nursing home residency and bedridden functional status is shown in figure 2. Nursing home 
TABLE 1 Characteristics of patients included in the analysis at admission

\begin{tabular}{|c|c|c|c|c|}
\hline Subjects & 211708 & 229796 & 228090 & 669594 \\
\hline Females & 93550 (44.2) & $102455(44.6)$ & $100280(44.0)$ & 296285 (44.2) \\
\hline Age years & $72.97(70.50-75.45)$ & $72.78(70.36-75.19)$ & $72.69(70.28-75.10)$ & $72.81(71.40-74.22)$ \\
\hline Age $<65$ years & 47533 & 52765 & 53603 & 153901 \\
\hline Bedridden functional condition & $53965(25.5)$ & $56849(24.7)$ & 54561 (23.9) & $165375(24.7)$ \\
\hline Respiratory rate breaths $\min ^{-1}$ & 22.27 (21.96-22.58) & $22.23(21.94-22.53)$ & $22.13(21.84-22.42)$ & 22.13 (22.04-22.38) \\
\hline Systolic blood pressure $\mathrm{mmHg}$ & $129.38(129.27-129.48)$ & $129.48(129.38-13)$ & $129.80(129.69-129.90)$ & 129.55 (129.50-129.61) \\
\hline Diastolic blood pressure $\mathrm{mmHg}$ & $74.31(74.25-74.37)$ & $74.17(74.11-74.22)$ & 74.27 (74.21-74.33) & $74.25(74.22-74.28)$ \\
\hline Mental confusion & $17787(8.4)$ & $18296(8.0)$ & $17454(7.7)$ & $53537(8.0)$ \\
\hline
\end{tabular}

Data are presented as $\mathrm{n}, \mathrm{n}(\%)$ or mean $(95 \% \mathrm{Cl})$. NHAP: nursing home-acquired pneumonia; CRB-65: confusion, respiratory frequency $\geqslant 30$ breaths.min ${ }^{-1}$, systolic blood pressure $<90 \mathrm{mmHg}$ or diastolic blood pressure $\leqslant 60 \mathrm{mmHg}$ and age $\geqslant 65$ years; RC: risk class.

residency was also associated with excess mortality in those without bedridden functional status; however, the difference in mortality decreased in the higher age decades.

The mortality rates according to CRB-65 risk classes across the three different CAP entities are shown in table 2.

\section{Factors associated with in-hospital mortality of patients admitted with CAP}

Age grouped in decades, CRB, nursing home residency and bedridden functional status were included in a multivariable analysis. All were independently associated with death (table 3).

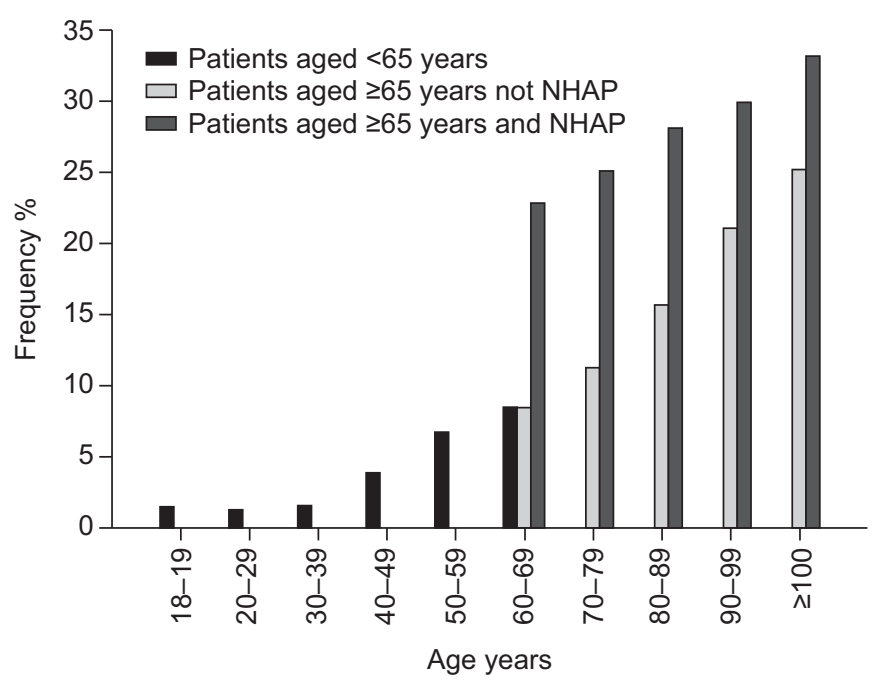

FIGURE 1. Mortality according to age groups in patients aged $<65$ years $\geqslant 65$ years not residing in nursing homes and $\geqslant 65$ years with nursing homeacquired pneumonia (NHAP).

\section{Predictions of in-hospital mortality according to varying CRB-age groups in the general population}

According to ROC analysis, the AUC improved with each age group until $\geqslant 80$ years (AUC 0.690, 95\% CI 0.688-0.691). However, the differences to CRB-65 were minimal (AUC $0.684,95 \%$ CI $0.682-0.685$ ) (table 4 ).

Looking at CRB-age risk group classifications, CRB-30, -40 and -50 seemed to confer equally the optimal balance between identification of low-risk patients $(0.65,0.71$ and $1.28 \%$ deaths in CRB-30, -40 and -50 RC-1, respectively; negative predictive value $99.3 \%, 99.3 \%$ and $98.7 \%$, respectively) and moderateand high-risk patients $(12.17-12.9 \%$ and $36.19-36.81 \%$ deaths in

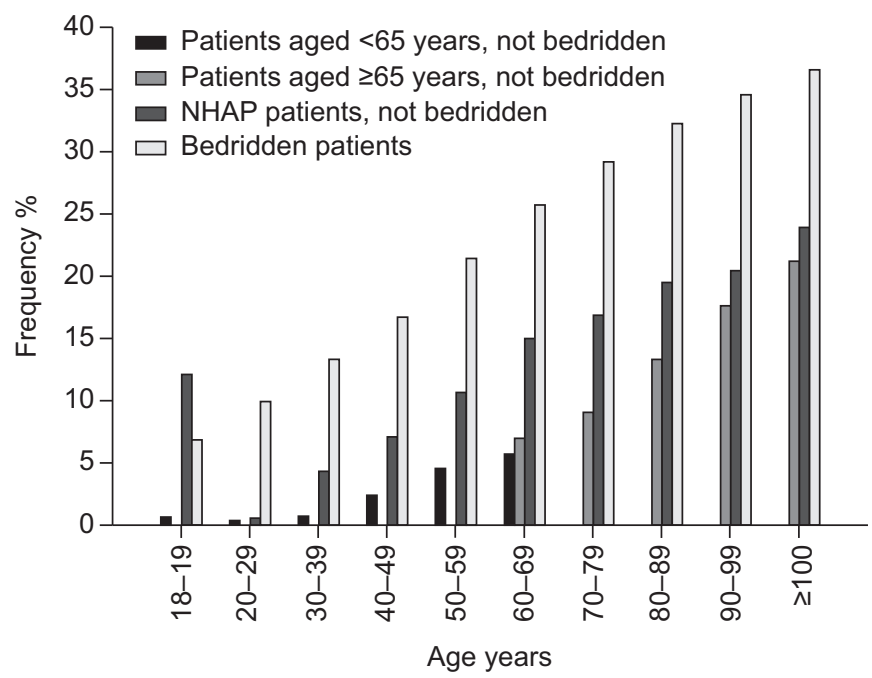

FIGURE 2. Mortality according to age groups and functional bedridden status in patients aged $<65$ years, $\geqslant 65$ years not residing in nursing homes and not bedridden, having nursing home-acquired pneumonia (NHAP) and not bedridden, and bedridden status regardless of age and residency. 
TABLE 2 Total in-hospital mortality according to CRB-65 score in different entities of community-acquired pneumonia

\begin{tabular}{lcccc} 
& Mortality & CRB-65 RC-1 & CRB-65 RC-2 & CRB-65 RC-3 \\
\hline Age $<\mathbf{6 5}$ years & $7943(5.2)$ & $3171(2.9)$ & $3795(9.2)$ & $977(23.2)$ \\
Age $\geqslant \mathbf{6 5}$ years & $86015(16.7)$ & NA & $67510(14.4)$ & $18505(21.5)$ \\
Age $\geqslant \mathbf{6 5}$ years not NHAP & $49443(13.0)$ & NA & $38825(11.1)$ & $10618(34.6)$ \\
Age $\geqslant \mathbf{6 5}$ years and NHAP & $36572(27.3)$ & NA & $28685(24.4)$ & $7887(46.9)$ \\
\hline
\end{tabular}

Data are presented as $\mathrm{n}(\%)$. CRB-65: confusion, respiratory frequency $\geqslant 30$ breaths $\cdot \mathrm{min}^{-1}$, systolic blood pressure $<90 \mathrm{mmHg}$ or diastolic blood pressure $\leqslant 60 \mathrm{mmHg}$ and age $\geqslant 65$ years; RC: risk class; NHAP: nursing home-acquired pneumonia; NA: not applicable.

CRB-30, -40 and $-50 \mathrm{RC}-2$ and -3 , respectively) (online supplementary table S1).

\section{Predictions of in-hospital mortality according to varying CRB-age groups in three CAP entities}

In the age group $<65$ years, ROC analysis showed that the AUC was best for age group $\geqslant 50$ years $(0.730,95 \%$ CI $0.724-$ 0.736) (table 4). This age threshold resulted in a mortality prediction of 1.28 for RC-1, 5.68\% for RC-2 and $23.29 \%$ for RC-3 (online supplementary table S2). The negative predictive value of CRB-50 was $98.7 \%$.

In the age group $\geqslant 65$ years not residing in nursing homes, the AUC was best for age group $\geqslant 80$ years $(0.663,95 \% \mathrm{CI}$ 0.660-0.655), which was similar to the general population (table 3). However, although the predictions of mortality of CRB-80 still followed a three-class pattern, the risk of death was already considerably high in RC-1 (6.62\%). Death in RC-2 was $14.38 \%$ and in RC-3 was $38.5 \%$ (online supplementary table S3).

In age group $\geqslant 65$ years with NHAP, the best AUC was also at $\geqslant 80$ years, but was lower than in the general population (0.608, 95\% CI 0.605-0.611) (table 4). Moreover, the CRB-80 no longer identified low-risk patients (RC-1 18.23\%, RC-2 32.08\% and RC-3 48.91\%) (online supplementary table S4).

Overall, predictions of CRB were identical to those of CRB-65. Variations of age groups with CRB improved AUC in the younger age group $<65$ years (if set as CRB-50), but impacted AUC only marginally in the elderly (if set as CRB-80) (table 4).

\begin{tabular}{lll}
\hline TABLE 3 & $\begin{array}{l}\text { Multivariable analysis of factors associated with } \\
\text { in-hospital death in patients admitted with } \\
\text { community-acquired pneumonia }\end{array}$ \\
Variable & OR $\mathbf{( 9 5 \% ~ C l )}$ & p-value \\
\hline Age decades & $1.38(1.37-1.39)$ & $<0.0001$ \\
Nursing home residency & $1.27(1.25-1.29)$ & $<0.0001$ \\
Bedridden functional status & $2.93(2.89-2.98)$ & $<0.0001$ \\
CRB score & $1.73(1.72-1.75)$ & $<0.0001$ \\
\hline
\end{tabular}

CRB: confusion, respiratory frequency $\geqslant 30$ breaths $\cdot \mathrm{min}^{-1}$, systolic blood pressure $<90 \mathrm{mmHg}$ or diastolic blood pressure $\leqslant 60 \mathrm{mmHg}$.

\section{DISCUSSION}

The most important results of our investigation are: 1) age was an independent predictor of death together with nursing home residency, functional status and CRB; 2 ) age group $\geqslant 65$ years (resulting in CRB-65) was a reasonable threshold for the assessment of the risk of death from CAP in the total population, although age group $\geqslant 80$ years (CRB-80) had the highest AUC; $3)$ in patients aged $<65$ years, the optimal AUC was at $\geqslant 50$ years (CRB-50), with excellent prediction of low-risk patients; 4) in patients aged $\geqslant 65$ years but not residing in nursing homes, age group $\geqslant 80$ years (CRB-80) provided the best predictions; however, low-risk patients were already at a $6.6 \%$ risk of death; 5 ) in patients aged $\geqslant 65$ years with NHAP, the optimal age group continued to be $\geqslant 80$ years (CRB-80); however, AUC was significantly worse than in those without NHAP. The CRB-80 score no longer predicted low-risk patients.

In this large population comprising virtually all hospitalised patients with CAP over the course of 3 years in Germany, age was an independent prognostic factor of in-hospital death in patients admitted with CAP. This is in contrast to several previous much smaller reports based on 30-day mortality [4-6]. Since comorbidity was not systematically recorded, we cannot determine the exact impact of age in relation to comorbidity. However, age remained an independent predictor of death together with nursing home residency and functional status, as well as severity criteria (CRB). This finding underlines the importance of identifying the optimal threshold for severity rules including age as a predictive factor.

Our data confirm the generally favourable operative characteristics of the CRB-65 score in the prediction of in hospital death from CAP in the general population. The AUC is somewhat lower than reported previously, probably because we relied on in-hospital and not 30-day mortality and we included NHAP and bedridden patients in the general population with CAP. Although CRB-80 had an even better AUC, the difference is most probably irrelevant in clinical terms.

A different view is provided if the CRB score is applied in three sub-populations, which, according to our data, should be regarded separately. The younger group aged $<65$ years had the optimal AUC in the age group $\geqslant 50$ years (resulting in CRB-50). The AUC was even superior to that of CRB-65 in the general population. The sharp increase in risk of death starting in the sixth decade is already obvious. In fact, the score provides an excellent tool for the identification of low-risk patients, with a minimal mortality in RC-1. Of note, despite a 


\begin{tabular}{|c|c|c|c|c|}
\hline TABLE 4 & $\begin{array}{l}\text { der the curve by } \\
\text { in nursing homes }\end{array}$ & $\begin{array}{l}\text { s in the total pop } \\
\text { aged } \geqslant 65 \text { years }\end{array}$ & $\begin{array}{l}\text {, patients aged }<65 \text { years, } t \\
\text { nursing home-acquired pneu }\end{array}$ & $\begin{array}{l}\text { e aged } \geqslant 65 \text { years not } \\
\text { nia (NHAP) }\end{array}$ \\
\hline CRB-age class & Total population & Age $<65$ years & Age $\geqslant 65$ years excluding NHAP & Age $\geqslant 65$ years and NHAP \\
\hline CRB & $0.684(0.682-0.685)$ & $0.681(0.674-0.688)$ & $0.642(0.639-0.645)$ & $0.607(0.604-0.610)$ \\
\hline CRB-30 & $0.652(0.650-0.654)$ & $0.698(0.692-0.704)$ & NA & NA \\
\hline CRB-40 & $0.659(0.657-0.661)$ & $0.718(0.712-0.724)$ & NA & NA \\
\hline CRB-60 & $0.679(0.677-0.681)$ & $0.705(0.698-0.711)$ & NA & NA \\
\hline CRB-65 & $0.684(0.682-0.685)$ & $0.681(0.674-0.688)$ & $0.642(0.639-0.645)$ & $0.607(0.604-0.610)$ \\
\hline CRB-70 & $0.688(0.687-0.690)$ & NA & $0.651(0.648-0.653)$ & $0.608(0.605-0.612)$ \\
\hline CRB-80 & $0.690(0.688-0.691)$ & NA & $0.663(0.660-0.655)$ & $0.608(0.605-0.611)$ \\
\hline CRB-90 & $0.662(0.660-0.664)$ & NA & $0.652(0.649-0.655)$ & $0.605(0.602-0.609)$ \\
\hline CRB-100 & $0.647(0.645-0.649)$ & NA & $0.642(0.639-0.645)$ & $0.607(0.604-0.611)$ \\
\hline
\end{tabular}

Data are presented as area under the curve $(95 \% \mathrm{Cl})$. Bold text represents the best threshold. CRB: confusion, respiratory frequency $\geqslant 30$ breaths $\cdot \mathrm{min}^{-1}$, systolic blood pressure $<90 \mathrm{mmHg}$ or diastolic blood pressure $\leqslant 60 \mathrm{mmHg}$ score; NA: not applicable

very low overall mortality rate, patients in RC-2 and -3 had already a considerable risk of death.

In patients aged $\geqslant 65$ years, independent of residential status, age group $\geqslant 80$ years had the optimal AUC. Whereas prediction of CRB-80 in the population not residing in nursing homes was similar to that of the general population, it was clearly inferior in patients with NHAP. Moreover, prediction of lowrisk patients was clearly inferior, and although CRB-80 still resulted in a three risk-class pattern, it frankly failed to identify low-risk NHAP patients, with mortality in "low" RC-1 already being very high.

These results are in line with other reports hinting at an inferiorto-unacceptable operative performance of $C(U) R B$ criteria $[5,10]$ and C(U)RB-65 in elderly patients [4, 11]. For example, PARSONAGE et al. [11] found CURB-65 to be unreliable for the prediction of low risk in elderly patients, with mortality reaching $27 \%$ in the low-risk category in patients aged $\geqslant 80$ years. In another study by CHEN et al. [4] including in- and outpatients, the performance of both severity scores (CURB-65 and PSI) became significantly inferior with growing age: AUCs for CURB-65 were 0.80 (95\% CI 0.67-0.93), 0.73 (95\% CI 0.65-0.82) and 0.60 (95\% CI $0.47-0.73)$ in the younger adult, elderly and very old patients, respectively. The AUC for the very old mirrored that in our investigation for NHAP patients. Prediction of low-risk patients was clearly worse in the very old. The authors claimed that raising the cut-off for age in the CURB-age score would improve predictions of mortality in the elderly. Our data confirm this, and go further, in that they show that lowering the age cut-off in the younger population, equally, generates better predictions. TERAMOTO et al. [3] suggested increasing the cut-off to 80 years in the elderly population.

Thus, the good performance of the CRB-65 severity score in the general population with hospitalised CAP is mainly due to the inclusion of a younger population with much lower risk of mortality. We, therefore, would advocate abandoning the CRB65 score in the younger population in a hospital setting. Instead, the CRB-50 score may be implemented in younger patients. The CRB-50 performs significantly better in the younger population than the CRB-65 score in the general population, and it perfectly identifies low-risk patients. In contrast, although the CRB-80 score in those aged $\geqslant 65$ years performs somewhat better compared to the CRB-65 in the general population, this difference is probably irrelevant in clinical practice. Of importance, the CRB-65 in those aged $\geqslant 65$ years no longer identifies a low-risk group. This, of course, does not mean that any patient aged $\geqslant 65$ years must be hospitalised, but it may increase attention to individual risk factors that might support such a treatment setting. These risk factors primarily include comorbidities. Alternative risk scores in the elderly (such as SOAR (systolic blood pressure, oxygenation, age and respiratory rate) and A-DROP (age, dehydration, respiratory failure, orientation disturbance and low blood pressure)) have not been shown convincingly to be superior to CURB-65 [6, 12].

Conversely, no CRB-age group seems to be of much value in patients aged $\geqslant 65$ years with NHAP. Predictions are moderate at best, and the score fails to identify low-risk patients. Therefore, more extensive modifications or even an alternative risk score is needed for the evaluation of such patients. Functional disability has repeatedly been shown to be the main predictor of death in this patient population $[13,14]$. The PSI risk score was shown to perform better when performance status was included [15]. A multidimensional prognostic index, calculated from information collected in a comprehensive geriatric assessment, accurately stratified hospitalised elderly patients into groups at varying risk of mortality, and the predictive accuracy was even higher than the predictive value of the PSI [16].

Recent data from primary care confirm that CRB-65 performed satisfactorily to identify low-risk patients, including in the elderly [17]. Evidently, different settings must be interpreted accordingly. However, whether CRB-65 still is the optimal tool for patients with CAP managed in primary care remains to be determined.

An alternative way to revise the CRB-age group score and possibly improve its predictions would be a transformation of age into a continuous variable as suggested by others [18]. 
However, such a transformation has the drawback of loss of simplicity and would require electronic support, without relevant improvement in predictions.

Risk of mortality is not the only assessment that has to be made initially. In many patients of this group, risk assessment must be combined with an early (and perhaps continuous) assessment of treatment aims and possible limitations due to ethical reasons. Moreover, increased risk of mortality is not generally linked to an inclination to hospitalise, but may imply just the reverse, e.g. it has been shown that hospitalisation may even worsen functional status, and that many patients would prefer home care [19]. Much work is still needed to define the optimal risk assessment in these patients.

Our data are particularly strong due to the enormous number of patients and the fact that all hospitalised patients of a large Western country during a 3-year period are included. Although data validity was not formally assessed, age is obviously a robust parameter. Potential faults in CRB criteria remain equally distributed and cannot have affected the influence of age groups in the CRB score in our analysis. In view of mortality rates comparable to many previous studies [1,2], the external validity of our data is obviously very high, at least for Western countries. A limitation is that we ignore the validity of ICD codes for the identification of CAP. Prior studies from outside Germany evaluating far less complex ICD search procedures than those applied in our programme suggest that their accuracy is modest $[20,21]$. At present, we cannot imagine an alternative approach that would be practical when performing such a nationwide programme. In view of the extremely large number of patients included, the impact of misclassification on our results is judged to be probably limited. Unfortunately, our database does not allow for a comparison of CRB-age groups with CURB-age groups and PSI, so we ignore whether other severity assessment tools would achieve better predictions. However, it is expected that the impact of age thresholds on CURB-65 would be similar to that resulting in our analysis of CRB-65.

In conclusion, based on these data, we recommend a revision in risk assessment of patients with hospitalised CAP. Patients aged $<65$ years may ideally be assessed by the CRB- 50 score, and lowrisk patients evidently have a very low risk of death. Those aged $\geqslant 65$ years not residing in nursing homes can be assessed by the CRB-65 score; however, low-risk patients are already at increased risk of death. NHAP patients need a different approach, and even if CRB-80 is used, initial risk assessment should be accompanied by the evaluation of functional status and comorbidity together with a consideration of treatment aims.

\section{STATEMENT OF INTEREST}

Conflict of interest information can be found alongside the online version of this article at www.erj.ersjournals.com

\section{REFERENCES}

1 Lim WS, van der Eerden MM, Laing R, et al. Defining community acquired pneumonia severity on presentation to hospital: an international derivation and validation study. Thorax 2003; 58: 377-382.

2 Fine MJ, Auble TE, Yealy DM, et al. A prediction rule to identify low-risk patients with community-acquired pneumonia. $N$ Engl J Med 1997; 336: 243-250.
3 Teramoto S, Yamamoto H, Yamaguchi Y, et al. Lower respiratory tract infection outcomes are predicted better by an age $>80$ years than by CURB-65. Eur Respir J 2008; 31: 477-478.

4 Chen J, Chang S, Chan R, et al. Comparison of clinical characteristics and performance of pneumonia severity score and CURB-65 among adult, elderly, and very old population. Thorax 2010; 65: 971-977.

5 Lim WS, Macfarlane JT. Defining prognostic factors in the elderly with community acquired pneumonia: a case controlled study of patients aged $\geqslant 75$ years. Eur Respir J 2001; 17: 200-205.

6 Mint PK, Kamath AV, Vowler SL. British Thoracic Society. Severity assessment criteria recommended by the British Thoracic Society (BTS) for community-acquired pneumonia (CAP) and older patients. Should SOAR (systolic blood pressure, oxygenation, age and respiratory rate) criteria be used in older people? A compilation study of two prospective cohorts. Age Ageing 2006; 35: 286-291.

7 Klapdor B, Ewig S, Pletz MW, et al. Community-acquired pneumonia in younger patients is an entity on its own. Eur Respir J 2012; 39: 1156-1161.

8 Ewig S, Klapdor B, Pletz MW, et al. Nursing home acquired pneumonia in Germany. An eight year prospective multicenter study. Thorax 2012; 67: 132-138.

9 Ewig S, Birkner N, Strauss R, et al. New perspectives on community-acquired pneumonia in 388,406 patients. Results from a nationwide mandatory performance measurement programme in healthcare quality. Thorax 2009; 64: 1062-1069.

10 Ewig S, Kleinfeld T, Bauer T, et al. Comparative validation of prognostic rules for community-acquired pneumonia in an elderly population. Eur Respir J 1999; 14: 370-375.

11 Parsonage $M$, Nathwani $D$, Davey $P$, et al. Evaluation of the performance of CURB-65 with increasing age. Clin Microbiol Infect 2009; 15: 858-864.

12 Shindo $\mathrm{Y}$, Sato S, Maruyama E, et al. Comparison of severity scoring systems A-DROP and CURB-65 for community-acquired pneumonia. Respirology 2008; 13: 731-735.

13 Torres $\mathrm{OH}$, Muñoz J, Ruiz D, et al. Outcome predictors of pneumonia in elderly patients: importance of functional assessment. J Am Geriatr Soc 2004; 52: 1603-1609.

14 Mody L, Sun R, Bradley SF. Assessment of pneumonia in older adults: effect of functional status. J Am Geriatr Soc 2006; 54: 1062-1067.

15 Naito $T$, Suda $T$, Yasuda $K$, et al. A validation and potential modification of the pneumonia severity index in elderly patients with community-acquired pneumonia. J Am Geriatr Soc 2006; 54: 1212-1219.

16 Pilotto A, Addante F, Ferrucci L, et al. The multidimensional prognostic index predicts short- and long-term mortality in hospitalized geriatric patients with pneumonia. J Gerontol A Biol Sci Med Sci 2009; 64: 880-887.

17 Bont J, Hak E, Hoes AW, et al. Predicting death in elderly patients with community-acquired pneumonia: a prospective validation study reevaluating the CRB-65 severity assessment tool. Arch Intern Med 2008; 168: 1465-1468.

18 Jones BE, Jones J, Bewick T, et al. CURB-65 pneumonia severity assessment adapted for electronic decision support. Chest 2011; 140: 156-163.

19 Leff B, Burton L, Mader SL, et al. Comparison of functional outcomes associated with hospital at home care and traditional acute hospital care. J Am Geriatr Soc 2009; 57: 273-278.

20 Guevara RE, Butler JC, Marston BJ, et al. Accuracy of ICD-9-CM codes in detecting community-acquired pneumococcal pneumonia for incidence and vaccine efficacy studies. Am J Epidemiol 1999; 149: 282-289.

21 van de Garde EM, Oosterheert JJ, Bonten M, et al. International classification of diseases codes showed modest sensitivity for detecting community-acquired pneumonia. J Clin Epidemiol 2007; 60: 834-838. 